\title{
On the accuracy of thin-ice thickness retrieval using MODIS thermal imagery over Arctic first-year ice
}

\author{
Marko MÄKYNEN, Bin CHENG, Markku SIMILÄ \\ Marine Research Unit, Finnish Meteorological Institute, Helsinki, Finland \\ E-mail: marko.makynen@fmi.fi
}

\begin{abstract}
We have studied the accuracy of ice thickness $\left(h_{i}\right)$ retrieval based on night-time MODIS (Moderate Resolution Imaging Spectroradiometer) ice surface temperature $\left(T_{s}\right)$ images and HIRLAM (High Resolution Limited Area Model) weather forcing data from the Arctic. The study area is the Kara Sea and eastern part of the Barents Sea, and the study period spans November-April 2008-11 with 199 $h_{i}$ charts. For cloud masking of the MODIS data we had to use manual methods in order to improve detection of thin clouds and ice fog. The accuracy analysis of the retrieved $h_{\mathrm{i}}$ was conducted with different methods, taking into account the inaccuracy of the HIRLAM weather forcing data. Maximum reliable $h_{\mathrm{i}}$ under different air-temperature and wind-speed ranges was $35-50 \mathrm{~cm}$ under typical weather conditions (air temperature $<-20^{\circ} \mathrm{C}$, wind speed $<5 \mathrm{~m} \mathrm{~s}^{-1}$ ) present in the MODIS data. The accuracy is best for the $15-30 \mathrm{~cm}$ thickness range, $\sim 38 \%$. The largest $h_{\mathrm{i}}$ uncertainty comes from air temperature data. Our ice-thickness limits are more conservative than those in previous studies where numerical weather prediction model data were not used in the $h_{\mathrm{i}}$ retrieval. Our study gives new detailed insight into the capability of $T_{\mathrm{s}}$-based $h_{\mathrm{i}}$ retrieval in the Arctic marginal seas during freeze-up and wintertime, and should also benefit work where MODIS $h_{\mathrm{i}}$ charts are used.
\end{abstract}

\section{INTRODUCTION}

In the Arctic Ocean the ocean-atmosphere heat, momentum and gas exchanges are controlled by the sea-ice thickness distribution. Thin ice with a thickness of $<0.5 \mathrm{~m}$ produces strong heat and salt fluxes and affects the weather and deep water circulation in the Arctic. Spaceborne remote sensing of sea-ice thickness can be conducted based on Archimedes' law and satellite radar or laser altimeter measurements of freeboard (Laxon and others, 2003; Kwok and Rothrock, 2009). However, this method results in large relative errors for thin ice (Laxon and others, 2003). Passive microwave radiometer data at frequencies of 19,37 and $85 \mathrm{GHz}$ have been used to estimate thickness of thin ice up to $10-20 \mathrm{~cm}$ based on correlation between ice surface salinity (i.e. dielectric properties) and ice thickness (Martin and others, 2004; Nihashi and others, 2009; Singh and others, 2011; Tamura and Ohshima, 2011). However, Nihashi and others (2009) showed that at least $37 \mathrm{GHz}$ data cannot detect thin ice when that ice is covered with snow. Kaleschke and others (2012) demonstrated that lowerfrequency L-band radiometer data from the Soil Moisture and Ocean Salinity (SMOS) satellite can be used to retrieve sea-ice thickness up to $0.5 \mathrm{~m}$. The major drawbacks are the coarse resolution of the radiometer data, grid size of 12.5$35 \mathrm{~km}$, which prevents detection of smaller leads and polynyas, and the currently poorly known effect of snow cover on the thin-ice thickness estimation.

Correlation between sea-ice thickness and synthetic aperture radar (SAR) data has also been studied. For the Baltic Sea it was demonstrated that thickness estimation of deformed ice under dry snow conditions is possible through a statistical relationship between the ice freeboard and the radar backscatter (Similä and others, 2010). The variance of the mean freeboard, i.e. large-scale surface roughness, increases with increasing mean freeboard, and, as the surface roughness increases, the backscatter also increases. Nakamura and others (2006) found good correlation between the L- (0.87) and C-band (0.80) co-polarization ratio and the thickness of undeformed ice in the Sea of Okhotsk. Good correlation has also been found between Antarctic first-year pack-ice and fast-ice thickness and the C-band co-polarization ratio (Nakamura and others, 2009). The co-polarization ratio has little sensitivity to ice surface roughness and is related to variations in salinity, i.e. ice surface dielectric constant, that can be caused by changes in ice thickness (Wakabayashi and others, 2004). Airborne C-band polarimetric SAR data together with a theoretical backscattering model have been used to estimate ice thickness in the $0-10 \mathrm{~cm}$ range (Kwok and others, 1995). SAR-based methods for thin-ice thickness retrieval are still experimental, and no operational products are yet available.

The final option for spaceborne thin-ice thickness $\left(h_{\mathrm{i}}\right)$ estimation is based on the ice surface temperature, $T_{\mathrm{s}}$, from satellite thermal imagery and the ice surface heat balance equation (Yu and Rothrock, 1996). Major assumptions here are that the heat flux through the ice and snow is equal to the atmospheric flux, and snow and ice temperature profiles are linear. This method is based on the physical relationship between $T_{\mathrm{s}}$ and $h_{\mathrm{i}}$ and is well established in the literature. In addition, the microwave radiometer $h_{\mathrm{i}}$ estimation methods at frequencies of 19,37 and $85 \mathrm{GHz}$ are based on regression between the radiometer data and $T_{\mathrm{s}}$-based $h_{\mathrm{i}}$. The spatial resolution of $T_{\mathrm{s}}$-based $h_{\mathrm{i}}$ charts is $\sim 1 \mathrm{~km}$, which is fine enough for detection of all polynyas and leads with equivalent width. Drawbacks here are the need for external atmospheric forcing data and cold cloud-free conditions.

Here we study $h_{\mathrm{i}}$ retrieval using Moderate Resolution Imaging Spectroradiometer (MODIS) thermal imagery, and conduct detailed analysis on the accuracy of the retrieved $h_{\mathrm{i}}$ under different air temperature $\left(T_{\mathrm{a}}\right)$ regimes in the Arctic. The study area includes the Kara Sea and the eastern part of the Barents Sea (Fig. 1). The external forcing data for solving the surface heat balance come from a numerical weather prediction (NWP) model, HIRLAM (High Resolution Limited 


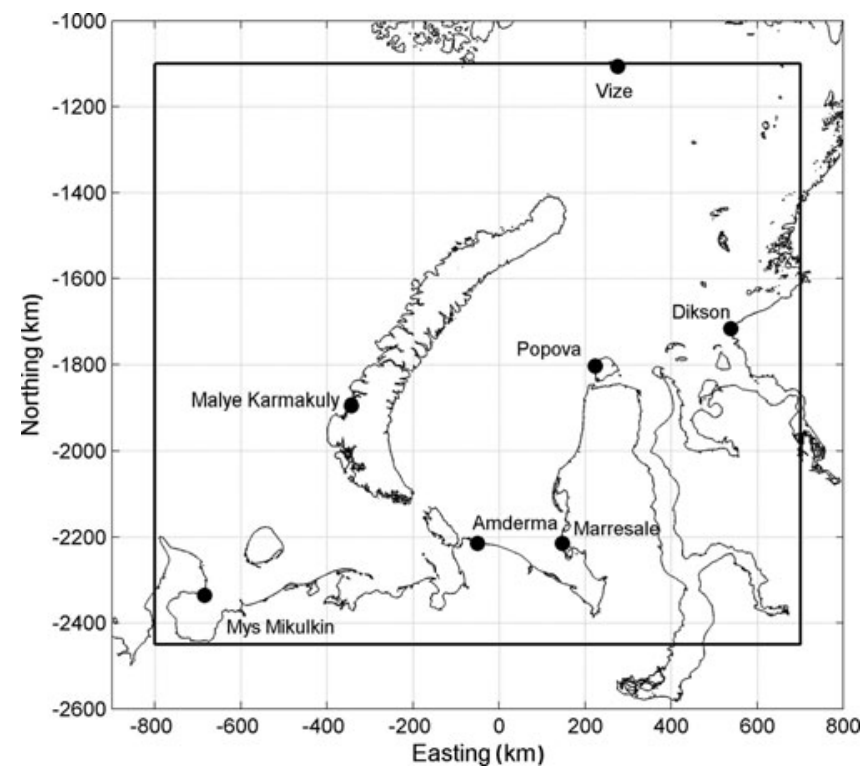

Fig. 1. Barents and Kara Seas study area for MODIS-based ice thickness retrieval. Rectangle shows the area, and dots are weather stations. Polar stereographic coordinates with mid-longitude of 63E.

Area Model) (Källen, 1996; Undén and others, 2002). The $h_{\mathrm{i}}$ estimates are obtained only from night-time MODIS data. Thus, the uncertainties related to the effect of the solar shortwave radiation and surface albedo are excluded. Snow vs ice thickness parameterization needed in the $h_{\mathrm{i}}$ retrieval was estimated from climatology and Russian Sever data (NSIDC, 2004). The cloud masking of the MODIS data was conducted using three spectral cloud tests and manual methods. Our MODIS $h_{\mathrm{i}}$ chart collection spans three winters (November-April) in 2008-11 with 199 charts.

The accuracy of the retrieved $h_{\mathrm{i}}$ is studied in the following ways:

1. Using estimated or guessed standard deviations and covariances of the input variables to the $h_{\mathrm{i}}$ retrieval, the $h_{\mathrm{i}}$ uncertainty is estimated with the Monte Carlo method. The accuracy of the HIRLAM data is studied by comparing them to coastal weather station data.

2. Thickness charts from consecutive days are compared to each other. Large differences are mainly due to the cloud-masking errors and HIRLAM data inaccuracies.

Method 2 has not been used in previous studies. Unfortunately, we do not yet have any in situ thickness data for the $h_{\mathrm{i}}$ validation. As another new method, the typical maximum reliable $h_{\mathrm{i}}$ under different $T_{\mathrm{a}}$ ranges is determined using not only the results from (1), but also the empirical mean $T_{\mathrm{a}}-T_{\mathrm{s}}$ vs $h_{\mathrm{i}}$ curves, which show how rapidly $h_{\mathrm{i}}$ changes as a function of a slight change in $T_{\mathrm{s}}$ or $T_{\mathrm{a}}$. We compare our $h_{\mathrm{i}}$ accuracy results and limits for the maximum reliable $h_{\mathrm{i}}$ to previous studies.

Unlike some previous studies (e.g. Yu and Rothrock, 1996; Tamura and others, 2006; Wang and others, 2010), we use here for the first time a large MODIS dataset (nearly 200 swath images) combined with numerical weather forcing data (HIRLAM) for the $h_{\mathrm{i}}$ retrieval and accuracy analysis of $h_{\mathrm{i}}$. We obtain uncertainty values for the weather forcing data by comparing them to the in situ weather data instead of using 'best-guess' values as in Yu and Rothrock
(1996) and Wang and others (2010). For the first time, we present $h_{\mathrm{i}}$ uncertainties and maximum reliable $h_{\mathrm{i}}$ values under different $T_{\mathrm{a}}$ and wind-speed ranges. In determining the maximum $h_{\mathrm{i}}$ we take into account the sensitivity of the retrieved $h_{\mathrm{i}}$ to a $T_{\mathrm{s}}$ or $T_{\mathrm{a}}$ change, which has not been done in previous studies. Our study gives new detailed insight into the capability of $T_{\mathrm{s}}$-based $h_{\mathrm{i}}$ retrieval in the Arctic marginal seas during freeze-up and wintertime, and should benefit work on microwave-radiometer-based thin-ice thickness retrieval where $T_{\mathrm{s}}$-based $h_{\mathrm{i}}$ charts are used for algorithm development and validation.

\section{DATA AND METHODS}

In the following, datasets and methods used in the ice thickness chart calculation are described.

\section{MODIS data}

MODIS spectrometer data were acquired from NASA's Warehouse Inventory Search Tool (WIST) service over our study area (Fig. 1) under cold cloud-free night-time conditions in November-April 2008-11. The MODIS data consist of level $1 \mathrm{~B}$ calibrated radiances at $1 \mathrm{~km}$ resolution (MOD02) and level 1A geolocation fields (MOD03). We chose to use only Terra MODIS data, as their acquisition times match those of Envisat advanced SAR (ASAR) Wide Swath Mode (WSM) images which will be combined with the MODIS data in a multisensor sea-ice thickness retrieval study by the authors. The MODIS acquisition times were 07:00-08:50 UTC (descending orbits) and 15:15-17:15 UTC (ascending orbits). After 15 March, only the afternoon MODIS data are utilized, as the sun zenith angle for the morning data becomes too low. After April, air temperature becomes too high for accurate $h_{\mathrm{i}}$ retrieval, and the sun zenith angle for the afternoon data becomes too low. The MODIS datasets with large cloud-free areas were visually identified using NASA's MOD29 product (MODIS/Terra Sea Ice Extent 5-Min L2 Swath 1 km) (Hall and others, 2007) and MODIS thermal RGB (red, green, blue) images. The total number of MODIS datasets here is 199. The MODIS data were rectified to a polar stereographic coordinate system (mid-longitude 63E, true-scale latitude $70 \mathrm{~N}$ ) with $1000 \mathrm{~m}$ pixel size using NASA's MODIS Swath Reprojection Tool.

\section{MODIS RGB images}

Two different RGB images were calculated from MODIS data: (1) brightness temperature bands 20 (red), 31 (green) and 32 (blue) (3.750, 11.030 and $12.020 \mu \mathrm{m})$, and (2) band difference 32-31, difference 31-22 and band 31 (this combination is used for the Meteosat SEVIRI (Spinning Enhanced Visible and Infrared Imager) instrument and is called NightMicrophysical). Both images are used in a manual cloud-masking procedure.

\section{MODIS cloud mask}

We used the following method for the cloud masking of night-time MODIS data. Based on a study of MODIS cloud masking (Frey and others, 2008) and our visual analysis of different cloud tests for the night-time data, we selected three cloud tests: (1) $11-3.9 \mu \mathrm{m}$ brightness temperature difference (BTD) for low clouds, (2) 3.9-12 $\mu \mathrm{m}$ BTD for high clouds, and (3) $6.7 \mu \mathrm{m}$ brightness temperature (BT) for high clouds. The thresholds for the tests were determined using empirical BT and BTD data for clouds and cloud-free sea ice 
and open water. The cloud tests are performed using $10 \times 10$ pixel blocks $(10 \mathrm{~km} \times 10 \mathrm{~km})$. If $10 \%$ or $20 \%$ of the block pixels are cloudy according to a cloud test, the block is labeled as cloudy. Next, morphological operations are performed to remove small isolated block groups (cloudy) and to fill isolated small holes (cloud-free). The results of the individual cloud tests are combined so that if a block is cloudy according to any cloud test then it is also cloudy in the combined mask. Clear restoration is conducted using $11 \mu \mathrm{m}$ brightness temperature (BT11) by reasoning that if under cold conditions BT11 is $>272 \mathrm{~K}$ it should represent cloud-free open water or very thin ice. After that, filling of the small holes is again conducted. Next, the following manual editing procedures can be conducted: filling holes, removing erroneous cloud mask elements, and masking arbitrary polygonal areas as cloudy or clear. The manual editing is conducted using the two RGB images described above. Finally, the $T_{\mathrm{s}}$ image is calculated and another round of manual cloud-mask editing is conducted using the $T_{\mathrm{s}}$ image and the two RGB images.

Our approach to the MODIS cloud masking yields a mask that is much less 'grainy' than a typical pixel-based mask (e.g. in the MOD29 product (Hall and others, 2007)). In addition, in our cloud mask, mask errors due to the MODIS sensor striping effect are not present. However, distinguishing clear sky from clouds is nowhere more difficult than in winter night-time conditions (Frey and others, 2008), and there are likely cases of unmasked thin clouds and fog in the $T_{\mathrm{s}}$ images.

\section{MODIS ice surface temperature}

The MODIS $T_{\mathrm{s}}$ under clear-sky conditions is obtained with a split-window technique, where 'split-window' refers to BTD in the $11-12 \mu \mathrm{m}$ atmospheric window (Hall and others, 2004). This technique allows for the correction of atmospheric effects primarily due to water vapor. The root-meansquare error (RMSE) of $T_{\mathrm{S}}$ is at least $1.3 \mathrm{~K}$ (Hall and others, 2004).

\section{HIRLAM}

HIRLAM is a short-range NWP model (Källen, 1996; Undén and others, 2002), developed by an international consortium of 11 European countries (http://hirlam.org). HIRLAM products are not routinely available over the Arctic Ocean, so we performed dedicated HIRLAM experiments over the research domain (Fig. 1) during November-April 2008-11. The experiments were run with the HIRLAM version 7.3newsnow, which contained improved surface parameterizations, including updated schemes for predicting snow and ice. Short forecasts with a lead time up to 9 hours were initialized every 6 hours (00, 06, 12 and 18 UTC). The horizontal resolution of the experiments was $7.5 \mathrm{~km}$, and the model had 60 levels in the vertical. Snow depth, sea surface temperature (SST) and ice cover analyses as well as soil temperature and moisture data assimilation were performed using optimal interpolation, based on SYNOP observations and European Centre for Medium-Range Weather Forecasts (ECMWF) SST/ice-cover analyses. Over our research domain, an average of seven SYNOP stations, located on the coastline and islands, reported surface weather observations every 3 hours. The HIRLAM upper-air analysis was replaced by an interpolation of the ECMWF analyses, which were also used as lateral boundaries for the HIRLAM experiment.

In the MODIS $T_{\mathrm{s}}$-based $h_{\mathrm{i}}$ retrieval, the following HIRLAM model parameters are used: air temperature at
$2 \mathrm{~m}$ height, wind speed at $10 \mathrm{~m}$, relative humidity at $2 \mathrm{~m}$ and downward longwave radiation. The parameters at 2 and $10 \mathrm{~m}$ heights are diagnostic variables obtained from the HIRLAM lowest-level $(\sim 32 \mathrm{~m})$ prognostic variables. In our polar stereographic coordinate system (mid-longitude 63E, true-scale latitude $70 \mathrm{~N}$ ) the HIRLAM parameters were interpolated to $20 \mathrm{~km}$ gridpoint spacing and to temporal resolution of 1 hour. For the $h_{\mathrm{i}}$ retrieval the HIRLAM parameters were further interpolated to the MODIS $1 \mathrm{~km}$ pixels using the nearest-neighbor method.

\section{Model relating sea-ice surface temperature and level ice thickness}

Level ice thickness from $T_{\mathrm{s}}$ can be estimated on the basis of a surface heat balance equation. Major assumptions here are that the heat flux through the ice and snow is equal to the atmospheric flux, and temperature profiles are linear in ice and snow (Yu and Rothrock, 1996). The heat balance equation at the top surface (whether sea ice or snow) during the night-time is (Yu and Rothrock, 1996)

$$
\left(F_{\mathrm{l}}^{\mathrm{up}}+F_{\mathrm{l}}^{\mathrm{dn}}+F_{\mathrm{s}}+F_{\mathrm{e}}\right)+F_{\mathrm{c}}=F_{\mathrm{t}}+F_{\mathrm{c}}=0,
$$

where $F_{I}^{\text {up }}$ and $F_{I}^{\text {dn }}$ are upward and downward longwave radiative fluxes, $F_{\mathrm{s}}$ and $F_{\mathrm{e}}$ are turbulent sensible and latent heat fluxes, and $F_{\mathrm{C}}$ is conductive heat flux approximated as

$$
\begin{aligned}
& F_{\mathrm{c}}=\gamma\left(T_{\mathrm{w}}-T_{\mathrm{s}}\right), \\
& \gamma=\frac{k_{\mathrm{i}} k_{\mathrm{s}}}{k_{\mathrm{s}} h_{\mathrm{i}}+k_{\mathrm{i}} h_{\mathrm{s}}},
\end{aligned}
$$

where $\gamma$ is the thermal conductance of the snow/ice sheet, $k_{\mathrm{i}}$ and $k_{\mathrm{s}}$ are heat conductivities of ice and snow, $h_{\mathrm{s}}$ is snow thickness and $T_{\mathrm{w}}$ is the freezing temperature of sea water approximated as $T_{\mathrm{w}}=-0.054 S_{\mathrm{w}}$, where $S_{\mathrm{w}}$ is the salinity of sea water. In Eqn (1), fluxes entering the top surface are positive ( $F_{1}^{\mathrm{dn}}$ always), and fluxes leaving the surface are negative ( $F_{1}^{\text {up }}$ always).

Based on the known $T_{\mathrm{s}}$, the surface heat fluxes and parameterized $h_{\mathrm{s}}, k_{\mathrm{i}}$ and $k_{\mathrm{s}}$ the estimation of $h_{\mathrm{i}}$ can be carried out. $F_{l}^{\text {up }}$ is obtained on the basis of MODIS-derived $T_{\mathrm{S}}$ assuming constant sea-ice thermal emissivity, $\varepsilon$, of 0.98 , and $F_{1}^{\text {dn }}$ is from the HIRLAM model. $F_{\mathrm{s}}$ and $F_{\mathrm{e}}$ are calculated as in $\mathrm{Yu}$ and Rothrock (1996) where the bulk transfer coefficients for heat and evaporation, $C_{\mathrm{s}}$ and $C_{\mathrm{e}}$, are assumed to be 0.003 for very thin ice and 0.00175 for thick ice. For $k_{\mathrm{s}}$ we assume a constant climatological value of $0.3 \mathrm{~W} \mathrm{~m} \mathrm{~K}^{-1}$ (Sturm and others, 1997). $k_{\mathrm{i}}$ is calculated using Untersteiner's (1964) equation and estimating ice bulk temperature, $T_{\mathrm{i}}$, with $T_{\mathrm{s}}$ as was done by $\mathrm{Yu}$ and Rothrock (1996). $k_{\mathrm{i}}$ also depends somewhat on bulk ice salinity, $S_{\mathrm{i}}$. According to the following general expression (Kovacs, 1996),

$$
S_{\mathrm{i}}=4.606+91.603 / h_{\mathrm{i}}
$$

$S_{\mathrm{i}}$ decreases from $13.8 \mathrm{ppt}$ to $6.4 \mathrm{ppt}$ when $h_{\mathrm{i}}$ increases from $10 \mathrm{~cm}$ to $50 \mathrm{~cm}$. To simplify the $h_{\mathrm{i}}$ retrieval and to take into account that $S_{\mathrm{i}}$ is in reality a complex function of sea-water salinity, ice growth rate and desalination processes, we always use in the $k_{\mathrm{i}}$ calculation an $S_{\mathrm{i}}$ value for $30 \mathrm{~cm}$ thick ice (7.7 ppt). The variation of $k_{\mathrm{i}}$ as a function of $S_{\mathrm{i}}$ is very small $(<10 \%)$ when $T_{\mathrm{i}}<268 \mathrm{~K}$ and $h_{\mathrm{i}}>10 \mathrm{~cm}$. When $T_{\mathrm{s}}$ is close to $T_{\mathrm{w}}$ (case of very thin ice under cold conditions) then $k_{\mathrm{i}}$ decreases rapidly as a function of $T_{\mathrm{s}}$. Thus, $k_{\mathrm{i}}$ is assumed to be constant when $T_{\mathrm{s}}<270 \mathrm{~K}$. 
For the $h_{\mathrm{i}}$ retrieval, a relationship between $h_{\mathrm{s}}$ and $h_{\mathrm{i}}$ is needed. If it is assumed to be linear of the form

$$
h_{\mathrm{s}}=b_{1} h_{i}
$$

then $h_{\mathrm{i}}$ is calculated from

$$
h_{\mathrm{i}}=\frac{k_{\mathrm{s}}}{k_{\mathrm{s}}+b_{1} k_{i}} H,
$$

where $H$ is so-called thermal ice thickness (effect of snow cover excluded),

$$
H=\frac{k_{\mathrm{i}}\left(T_{\mathrm{s}}-T_{\mathrm{w}}\right)}{F_{\mathrm{t}}} .
$$

There are a number of simplifications/approximations in the above approach, in order to minimize the difficulties in retrieving $h_{\mathrm{i}}$. The accuracy of the approach is highly sensitive with respect to the model parameterizations and the accuracy of the forcing data. In a previous study in the Arctic it was assessed that the $h_{\mathrm{i}}$ uncertainty increases from $27 \%$ for thin ice $(20 \mathrm{~cm})$ to $50 \%$ for $h_{\mathrm{i}}$ around $1 \mathrm{~m}$ during winter night-time conditions (Yu and Rothrock, 1996). The largest uncertainties came from $F_{I}^{\mathrm{dn}}$ and $F_{\mathrm{s}}$. It was concluded that $T_{\mathrm{s}}$-based $h_{\mathrm{i}}$ data can resolve the regional and seasonal variations in thin ice. A more recent study, utilizing the same method of $h_{\mathrm{i}}$ retrieval as Yu and Rothrock (1996) with the Advanced Very High Resolution Radiometer (AVHRR) Polar Pathfinder extended (APP-x) product (25 km pixel size), showed $h_{\mathrm{i}}$ estimation capability up to $\sim 2.8 \mathrm{~m}$ with an accuracy of $>80 \%$ (Wang and others, 2010). Passive microwave sea-ice concentration data were used to correct $T_{\mathrm{s}}$ by removing the $T_{\mathrm{w}}$ contribution from overall ice-covered pixel temperature. During the night-time the largest error sources were $h_{\mathrm{s}}$ cloud amount (related to $F_{\mathrm{I}}^{\mathrm{dn}}$ ) and wind speed. Yu and Rothrock (1996) used uncertainty estimates of the heat fluxes in the $h_{\mathrm{i}}$ accuracy analysis, but Wang and others (2010) used the variables of the heat fluxes. Neither study used NWP model data in the $h_{\mathrm{i}}$ retrieval. $T_{\mathrm{a}}$ was estimated as $T_{\mathrm{s}}$ average over a large area plus a climatological constant, and wind speed from the geostrophic wind. Tamura and others (2006) retrieved $h_{\mathrm{i}}$ using night-time AVHRR and ECMWF NWP data over an Antarctic polynya. The standard deviation of the difference between the retrieved $h_{\mathrm{i}}$ and in situ data $\left(\max h_{\mathrm{i}} 0.3 \mathrm{~m}\right)$ was only $2 \mathrm{~cm}$. In addition, AVHRR and ship-borne radiation thermometerbased $h_{\mathrm{i}}$ retrievals matched each other.

In general, the $h_{\mathrm{i}}$ accuracy decreases as $h_{\mathrm{i}}$ increases, and the accuracy and the maximum retrievable $h_{\mathrm{i}}$ decreases as weather gets warmer, as $T_{\mathrm{s}}$ then saturates at smaller $h_{\mathrm{i}}$ and the $T_{\mathrm{s}}$ contrast between different ice thicknesses decreases. The above approach for $T_{\mathrm{s}}$-based $h_{\mathrm{i}}$ retrieval is only valid for smooth thermodynamically grown ice.

\section{Coastal weather station data}

There are seven coastal weather stations in our study area (Fig. 1). Weather observations were conducted at 0, 6, 12 and $18 \mathrm{~h}$ UTC. Air temperature at $2 \mathrm{~m}$, wind speed at $10 \mathrm{~m}$ and relative humidity at $2 \mathrm{~m}$ are used to study the accuracy of the HIRLAM model data.

\section{RESULTS AND DISCUSSION}

The construction of the MODIS $T_{\mathrm{s}}$-based ice thickness chart starts with the determination of a statistical relationship between $h_{\mathrm{s}}$ and $h_{\mathrm{i}}$. Next, the accuracy of the HIRLAM forcing data needed in the MODIS $T_{\mathrm{s}}$-based $h_{\mathrm{i}}$ retrieval is studied. This is followed by presentation of the MODIS $h_{\mathrm{i}}$ charts, and detailed accuracy analysis of the $h_{\mathrm{i}}$ charts with different methods. Typical maximum reliable $h_{\mathrm{i}}$ is also estimated.

\section{Statistical relationship between snow and ice thickness}

Yu and Rothrock (1996) used an empirical relationship between $h_{\mathrm{s}}$ and $h_{\mathrm{i}}$ by Doronin (1971) in retrieving $h_{\mathrm{i}}$ from the AVHRR data:

$$
\begin{aligned}
& h_{\mathrm{s}}=0 \text { for } h_{\mathrm{i}}<5 \mathrm{~cm} \\
& h_{\mathrm{s}}=0.05 h_{\mathrm{i}} \text { for } 5 \mathrm{~cm} \leq h_{\mathrm{i}} \leq 20 \mathrm{~cm} \\
& h_{\mathrm{s}}=0.1 h_{\mathrm{i}} \text { for } h_{\mathrm{i}}>20 \mathrm{~cm} .
\end{aligned}
$$

We utilize snow and ice thickness data from the Soviet Union's airborne Sever expeditions (NSIDC, 2004) conducted in 1950-89 to determine the relationship between $h_{\mathrm{s}}$ and $h_{\mathrm{i}}$. The Sever data represent late-winter conditions before the start of sea-ice melt. To estimate the $h_{\mathrm{s}}$ vs $h_{\mathrm{i}}$ relationship, we use only the so-called runway data up to $h_{\mathrm{i}}=100 \mathrm{~cm}$, which represent level ice, from a geographical area extending $200 \mathrm{~km}$ from the borders of our study area (Fig. 1). Data acquired after the end of April are not used, as this time period is not included in the MODIS datasets. The total number of data points is 322 . The data amount for $h_{\mathrm{i}}<40 \mathrm{~cm}$ is very small, only 23 data points. The linear regression fit to the data is

$$
h_{\mathrm{s}}=0.049 h_{\mathrm{i}}+3.3 \mathrm{~cm} \text {. }
$$

The coefficient of determination, $r^{2}$, is very small, only 0.04 , but the $p$-value is 0.00 , due to the large data scatter. Typically $h_{\mathrm{s}}<10 \mathrm{~cm}$ regardless of $h_{\mathrm{i}}$. Using Eqn (9), $h_{\mathrm{s}}=4.3 \mathrm{~cm}$ when $h_{\mathrm{i}}=20 \mathrm{~cm}$, whereas Eqn (8) yields $h_{\mathrm{s}}$ of only $1 \mathrm{~cm}$. For ice thinner than $40 \mathrm{~cm}$, Eqn (9) likely gives snow covers that are too thick.

Due to the small number of data and the large scatter of data points when $h_{\mathrm{i}} \leq 35 \mathrm{~cm}$, these data points probably do not have a large effect on the regression coefficients, as the few data points effectively cancel out each other's influence on the regression line. This was verified by fitting the regression line to data points with $h_{\mathrm{i}}>35 \mathrm{~cm}$. The results were equal to Eqn (9), indicating a robust fit to the dataset, particularly in this ice thickness range. Consequently, we combine the Sever data and Eqn (8) as follows: (1) the Sever data are divided into $10 \mathrm{~cm}$ thickness bins centered from $30 \mathrm{~cm}$ to $90 \mathrm{~cm}$, and the mean $h_{\mathrm{s}}$ and $h_{\mathrm{i}}$ are calculated; (2) at $h_{\mathrm{i}}$ values of 0,10 and $20 \mathrm{~cm}$, Eqn (8) is used; and (3) linear regression is fitted to these data points (Fig. 2). The regression fit is

$$
h_{\mathrm{s}}=0.09 h_{\mathrm{i}}+0.1 \mathrm{~cm} \text {. }
$$

The constant term is so small that it can be dropped. When $h_{\mathrm{i}}<20 \mathrm{~cm}$, Eqn (10) likely gives snow cover that is too thick, especially for polynyas. Thus, for this thickness range we use Eqn (8), yielding the following final $h_{\mathrm{i}}$ vs $h_{\mathrm{s}}$ relationship

$$
\begin{aligned}
& h_{\mathrm{s}}=0 \text { for } h_{\mathrm{i}}<5 \mathrm{~cm} \\
& h_{\mathrm{s}}=0.05 h_{\mathrm{i}} \text { for } 5 \mathrm{~cm} \leq h_{\mathrm{i}} \leq 20 \mathrm{~cm} \\
& h_{\mathrm{s}}=0.09 h_{\mathrm{i}} \text { for } h_{\mathrm{i}}>20 \mathrm{~cm} .
\end{aligned}
$$

The only difference between Eqns (11) and (8) is a $10 \%$ smaller slope term in Eqn (11) when $h_{\mathrm{i}}>20 \mathrm{~cm}$. 


\section{HIRLAM accuracy}

The accuracy of the HIRLAM air temperature, $T_{\mathrm{a}}^{\mathrm{H}}$, wind speed, $u^{\mathrm{H}}$, and relative humidity, $\mathrm{Rh}^{\mathrm{H}}$, are studied by comparing them to the coastal weather station data $\left(T_{\mathrm{a}}^{\mathrm{w}}, u^{\mathrm{w}}\right.$, $\mathrm{Rh}^{\mathrm{w}}$ ) from seven stations (Fig. 1). We do not have in situ data to make a comparison for the HIRLAM $F_{1}^{\text {dn }}$. In the comparison the HIRLAM data (1 hour time-step) from the gridpoints over the ocean closest to the weather stations and coincident with the weather station data (6 hour time step) were used. The comparison was conducted using HIRLAM and weather station datasets for winter 2010/11 (1 October30 April). Table 1 shows the comparison (HIRLAM minus weather station data) results: mean bias, RMSE, standard deviation (std) and their variation from station to station, and the correlation coefficient.

The overall mean bias of $T_{\mathrm{a}}^{\mathrm{H}}$ is $-0.9^{\circ} \mathrm{C}\left(T_{\mathrm{a}}^{\mathrm{H}}\right.$ is on average $0.9^{\circ} \mathrm{C}$ smaller than $T_{\mathrm{a}}^{\mathrm{w}}$ ). The overall RMSE and std are rather high, $3.8^{\circ} \mathrm{C}$ and $3.7^{\circ} \mathrm{C}$, but the correlation between the two $T_{\mathrm{a}}$ datasets is nonetheless 0.94 . The high correlation between $T_{\mathrm{a}}^{\mathrm{H}}$ and $T_{\mathrm{a}}^{\mathrm{w}}$ shows the peaks and lows of air-temperature changes are captured well by HIRLAM. There is some variation of the statistics from station to station (e.g. from $2.9^{\circ} \mathrm{C}$ to $4.2^{\circ} \mathrm{C}$ for std). The mean bias increases somewhat with decreasing $T_{\mathrm{a}}^{\mathrm{H}}$ : for the $T_{\mathrm{a}}^{\mathrm{H}}$ ranges -10 to $-5^{\circ} \mathrm{C}$ and -25 to $-20^{\circ} \mathrm{C}$, it is $-0.1^{\circ} \mathrm{C}$ and $-2.3^{\circ} \mathrm{C}$, respectively. Both RMSE and std increase with decreasing $T_{\mathrm{a}}^{\mathrm{H}}$ (e.g. in the above-mentioned $T_{\mathrm{a}}^{\mathrm{H}}$ ranges, RMSE is $3.0^{\circ} \mathrm{C}$ and $4.8^{\circ} \mathrm{C}$ ). This HIRLAM underestimation of $T_{\mathrm{a}}$ leads to underestimation of $h_{\mathrm{i}}$, as the $T_{\mathrm{a}}-T_{\mathrm{s}}$ difference now resembles that of thinner ice.

These differences between the two $T_{\mathrm{a}}$ datasets could be partly due to the sea-ice mask used in the HIRLAM model. The mask only shows either open water or thick sea ice, so the atmosphere over the sea ice is always insulated from the ocean regardless of the ice thickness. In addition, a modeling study by Lüpkes and others (2008) demonstrated that, for sea-ice concentrations greater than $90 \%$, small changes in the sea-ice fraction have a strong increasing effect on the near-surface $T_{\mathrm{a}}$ over thick ice under clear-sky conditions during polar night.

The correlation between the $u$ datasets is much lower than for the $T_{\mathrm{a}}$ datasets, only 0.67 . Because the wind speed changes at much higher temporal frequency than air temperature, the lower correlation between $u^{\mathrm{H}}$ and $u^{\mathrm{w}}$ does not indicate a weak modeling skill by the HIRLAM as our closer analysis showed. The overall mean bias of $u^{\mathrm{H}}$ is $-1.2 \mathrm{~m} \mathrm{~s}^{-1}$, std is $3.1 \mathrm{~m} \mathrm{~s}^{-1}$ and RMSE is $3.3 \mathrm{~m} \mathrm{~s}^{-1}$. These std and RMSE values indicate $>100 \%$ uncertainties $\left(\operatorname{std}\left(u^{\mathrm{H}}\right) / u^{\mathrm{H}}\right)$ for $u^{\mathrm{H}}$ at lower wind speeds. Thus, the std of $u^{\mathrm{H}}-u^{\mathrm{w}}$ was also studied as a function of $u^{\mathrm{H}}$. Std increases rapidly with increasing $u^{\mathrm{H}}$ up to $12 \mathrm{~m} \mathrm{~s}^{-1}$, but at the same time the $u^{\mathrm{H}}$ uncertainty decreases from $>100 \%$, when $u^{\mathrm{H}} \leq 2 \mathrm{~m} \mathrm{~s}^{-1}$, to

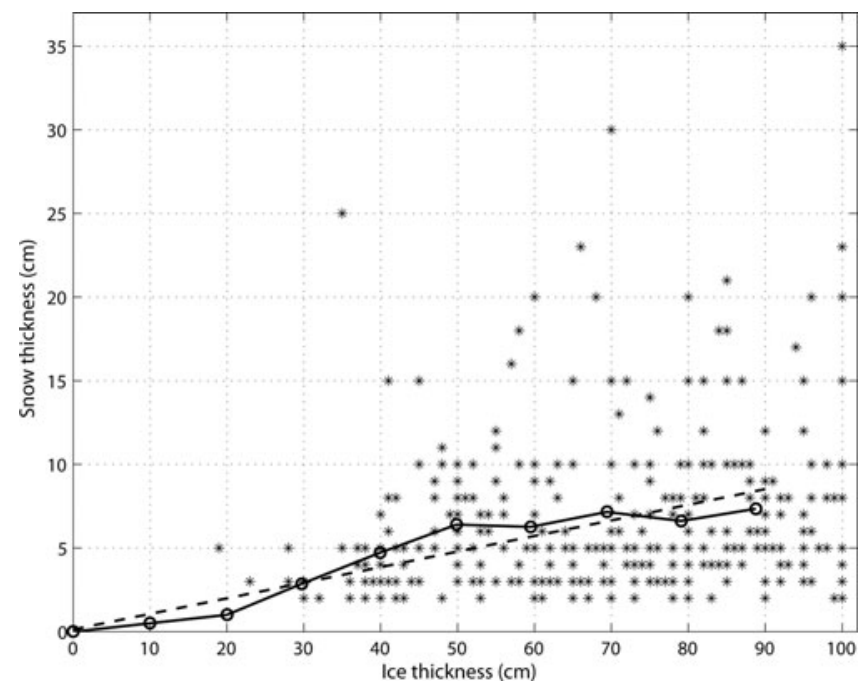

Fig. 2. The relationship between snow and ice thickness for level ice. Stars are the Sever data acquired in 1950-89 in our study area. The solid-dotted line is the average snow and ice thickness relationship using the Sever data for thickness range $30-90 \mathrm{~cm}$ and Doronin's (1971) empirical equation for $0-20 \mathrm{~cm}$ range. Dashed line is linear regression fit to the average data.

$\sim 40 \%$. When $u^{\mathrm{w}}>9 \mathrm{~m} \mathrm{~s}^{-1}$, HIRLAM mostly underestimates it. At low $u^{\mathrm{w}}\left(<3 \mathrm{~m} \mathrm{~s}^{-1}\right)$, by contrast, HIRLAM slightly overestimates it. During the acquisitions of the MODIS datasets, $u^{\mathrm{w}}$ was typically small: in the 2010-11 data the average was $5 \mathrm{~m} \mathrm{~s}^{-1}$ in the Kara Sea. The HIRLAM underestimation of $u$ leads to underestimation of absolute values of $F_{\mathrm{s}}$ and $F_{\mathrm{e}}$ which are linear functions of $u$. This in turn leads to either $h_{\mathrm{i}}$ overestimation if $F_{\mathrm{s}}+F_{\mathrm{e}}<0$, or underestimation if $F_{\mathrm{s}}+F_{\mathrm{e}}>0$.

The overall mean bias and std for $\mathrm{Rh}^{\mathrm{H}}-\mathrm{Rh}^{\mathrm{w}}$ is $+8 \%$ and $12 \%$, respectively. There is no correlation between the $\mathrm{Rh}$ datasets. HIRLAM significantly overestimates $\mathrm{Rh}$ when $\mathrm{Rh}^{\mathrm{w}}<80 \%$. Rh is the input parameter only for the turbulent latent flux, $F_{\mathrm{e}}$, whose contribution to the heat balance equation (1) is the smallest. In some previous studies, Rh has been simply assumed to be constant: $90 \%$ in $\mathrm{Yu}$ and Rothrock (1996) and Wang and others (2010).

For the std of the HIRLAM $F_{1}^{\text {dn }}$ we assume a value of $20 \mathrm{~W} \mathrm{~m}^{-2}$ based on a study where different $F_{1}^{\mathrm{dn}}$ schemes were compared to in situ $F_{\mathrm{I}}^{\mathrm{dn}}$ measurements on Baltic Sea ice (Zhang and others, 2006).

\section{MODIS ice thickness chart}

In calculating the MODIS $h_{\mathrm{i}}$ charts, the following restrictions and procedures are applied: (1) The MODIS sensor scan angle $\left(\max 55^{\circ}\right)$ of the $T_{\mathrm{s}}$ data is limited to be $<40^{\circ}$ in order to restrict the effect of atmosphere and deterioration of

Table 1. Comparison between seven weather stations and HIRLAM data (HIRLAM minus station) for air temperature, $T_{\mathrm{a}}\left({ }^{\circ} \mathrm{C}\right)$ ), wind speed, $u$ $\left(\mathrm{m} \mathrm{s}^{-1}\right)$, and relative humidity, Rh (\%). The time period is 1 October 2010 to 31 April 2011

\begin{tabular}{|c|c|c|c|c|c|c|c|}
\hline \multirow[t]{2}{*}{ Parameter } & \multicolumn{2}{|c|}{ Mean bias } & \multicolumn{2}{|c|}{ RMSE } & \multicolumn{2}{|c|}{ std } & \multirow[t]{2}{*}{ Correlation } \\
\hline & Overall & Variation & Overall & Variation & Overall & Variation & \\
\hline$T_{\mathrm{a}}$ & -0.9 & -2.1 to +1.0 & 3.8 & $3.1-4.7$ & 3.7 & $2.9-4.2$ & 0.94 \\
\hline$u$ & -1.2 & -2.4 to +0.7 & 3.3 & $2.4-4.6$ & 3.1 & $2.2-3.9$ & 0.67 \\
\hline $\mathrm{Rh}$ & +8 & +1 to +15 & 15 & 11-18 & 12 & 9-13 & -0.02 \\
\hline
\end{tabular}



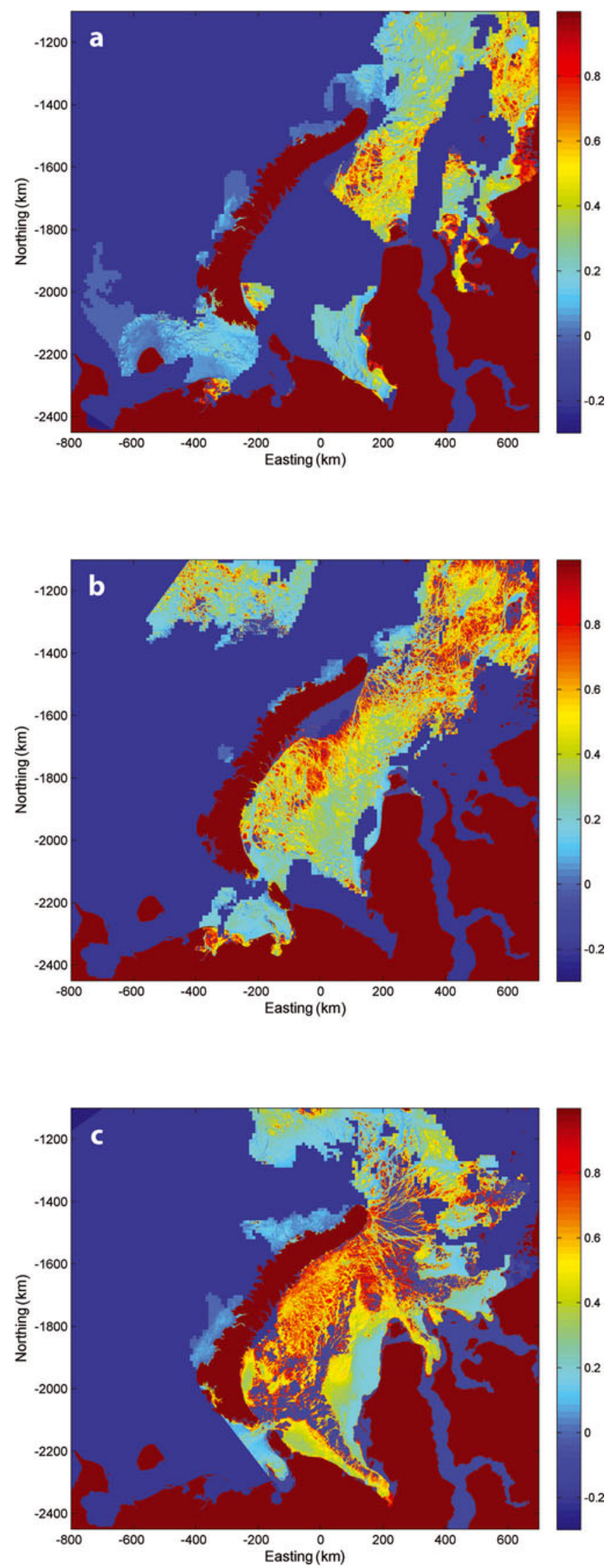

Fig. 3. Ice thickness charts derived from the MODIS ice surface temperature images acquired on (a) 31 December 2009, (b) 14 January 2010 and (c) 23 February 2010. Dark blue is either cloud (thickness $-0.2 \mathrm{~m})$, no data mask $(-0.3 \mathrm{~m})$ or scan angle mask $(-0.2 \mathrm{~m})$, and light blue $(-0.1 \mathrm{~m})$ indicates areas where ice thickness retrieval was unsuccessful or resulted in thickness values more than $1 \mathrm{~m}$. Polar stereographic coordinates with mid-longitude of $63 \mathrm{E}$. spatial resolution. At a scan angle of $40^{\circ}$ the across-track resolution is $\sim 2 \mathrm{~km}$ (at nadir it is $1 \mathrm{~km}$ ). (2) The calculated $h_{\mathrm{i}}$ is rounded to $1 \mathrm{~cm}$ resolution. (3) The $h_{\mathrm{i}}$ retrieval yields sometimes erroneous negative $h_{\mathrm{i}}$ values for thick ice $\left(F_{\mathrm{t}}>0\right.$ in Eqn (7) which is erroneous) due to errors either in the HIRLAM data or in the model parameterizations. These erroneous $h_{\mathrm{i}}$ values are flagged in the $h_{\mathrm{i}}$ chart. (4) For very thin ice (few cm), negative $h_{\mathrm{i}}$ values are sometimes obtained; these are marked to $0 \mathrm{~m}$ (i.e. open water). (5) Using $10 \times 10 \mathrm{~km}$ block averages of $T_{\mathrm{s}}$ and $T_{\mathrm{a}}$ the following changes are made to the calculated $h_{\mathrm{i}}$ chart: (a) If $T_{\mathrm{a}}>-5^{\circ} \mathrm{C}$ then the calculated $h_{\mathrm{i}}$ is masked away. It is assumed that at these high air temperatures the sensitivity of $h_{\mathrm{i}}$ to $T_{\mathrm{s}}$ is too small for accurate $h_{\mathrm{i}}$ retrieval. (b) If $T_{\mathrm{a}}>-5^{\circ} \mathrm{C}$ but $T_{\mathrm{s}}-T_{\mathrm{w}}>-1{ }^{\circ} \mathrm{C}$, then the block is flagged as open water. It is not possible to separate accurately open water and $1-3 \mathrm{~cm}$ thick ice due to the inaccuracies of the $T_{\mathrm{s}}$ and heat fluxes. (6) Finally, it is assumed that $h_{\mathrm{i}}$ values greater than $1.0 \mathrm{~m}$ are too unreliable and they are flagged away. Figure 3 shows examples of the calculated MODIS $h_{\mathrm{i}}$ charts.

The areal coverage percentage of the $h_{\mathrm{i}}$ charts over our study area (land excluded) varies from $5 \%$ to $45 \%$, with an average of $19 \%$. Here the areas of unsuccessful $h_{\mathrm{i}}$ retrieval are included, as they indicate areas of thick ice $\left(h_{\mathrm{i}}>1 \mathrm{~m}\right)$, although without any thickness estimate. Due to the MODIS scan angle limitation, a totally cloud-free MODIS $T_{\mathrm{s}}$ image (none was found) would cover, on average, only $77 \%$ of the study area. The percentage of $T_{\mathrm{s}}$ pixels for which the $h_{\mathrm{i}}$ retrieval was unsuccessful varied from $0 \%$ to $79 \%$, with an average of $18 \%$, and it increased from November to April as sea-ice thickness in general increases during the ice season due to thermodynamic growth and deformation. The average time difference between two MODIS $h_{\mathrm{i}}$ charts is 2.4 days, and the difference varies from 0.6 to 12.4 days. The temporal coverage is worst (fewest $h_{\mathrm{i}}$ charts) for November and April due to prevailing cloud cover, and best for February and March. The $h_{\mathrm{i}}$ chart coverage is most frequent over the northeastern part of the Kara Sea (top-right quarter in Fig. 1) and less frequent over the northwestern (Barents Sea) and southwestern (Pechora Sea) parts of our study area. The cloudiness frequency is hence very closely associated with the distance to open sea.

\section{Accuracy and maximum value of the MODIS-based ice thickness}

The accuracy of the MODIS $T_{\mathrm{s}}$-based $h_{\mathrm{i}}$ is studied in two ways: (1) Using estimated or guessed standard deviations and covariances of the input variables to the $h_{\mathrm{i}}$ retrieval, the $h_{\mathrm{i}}$ uncertainty is estimated with the Monte Carlo method. The uncertainty, or relative accuracy, is quantified with $\operatorname{std}\left(h_{\mathrm{i}}\right) /$ mean $\left(h_{\mathrm{i}}\right)$ of the sampled $h_{\mathrm{i}}$ values. (2) $h_{\mathrm{i}}$ charts from consecutive days are compared to each other. Large differences are mainly due to the cloud-masking errors, HIRLAM data inaccuracies and the frequency and spatial distribution of open leads. The comparison estimates stability of the $h_{\mathrm{i}}$ retrieval when the true $h_{\mathrm{i}}$ change is insignificant, but the forcing data and $T_{\mathrm{s}}$ may undergo significant changes in a short period of time. Currently we do not have any coincident in situ thickness data for accuracy studies.

The typical maximum reliable $h_{\mathrm{i}}$ under different $T_{\mathrm{a}}$ ranges is determined using not only the results of the above analyses, but also an empirical mean $T_{\mathrm{a}}-T_{\mathrm{s}}$ vs $h_{\mathrm{i}}$ relationship which shows how rapidly $h_{\mathrm{i}}$ changes as a function of a slight change of $T_{\mathrm{s}}$ or $T_{\mathrm{a}}$. 

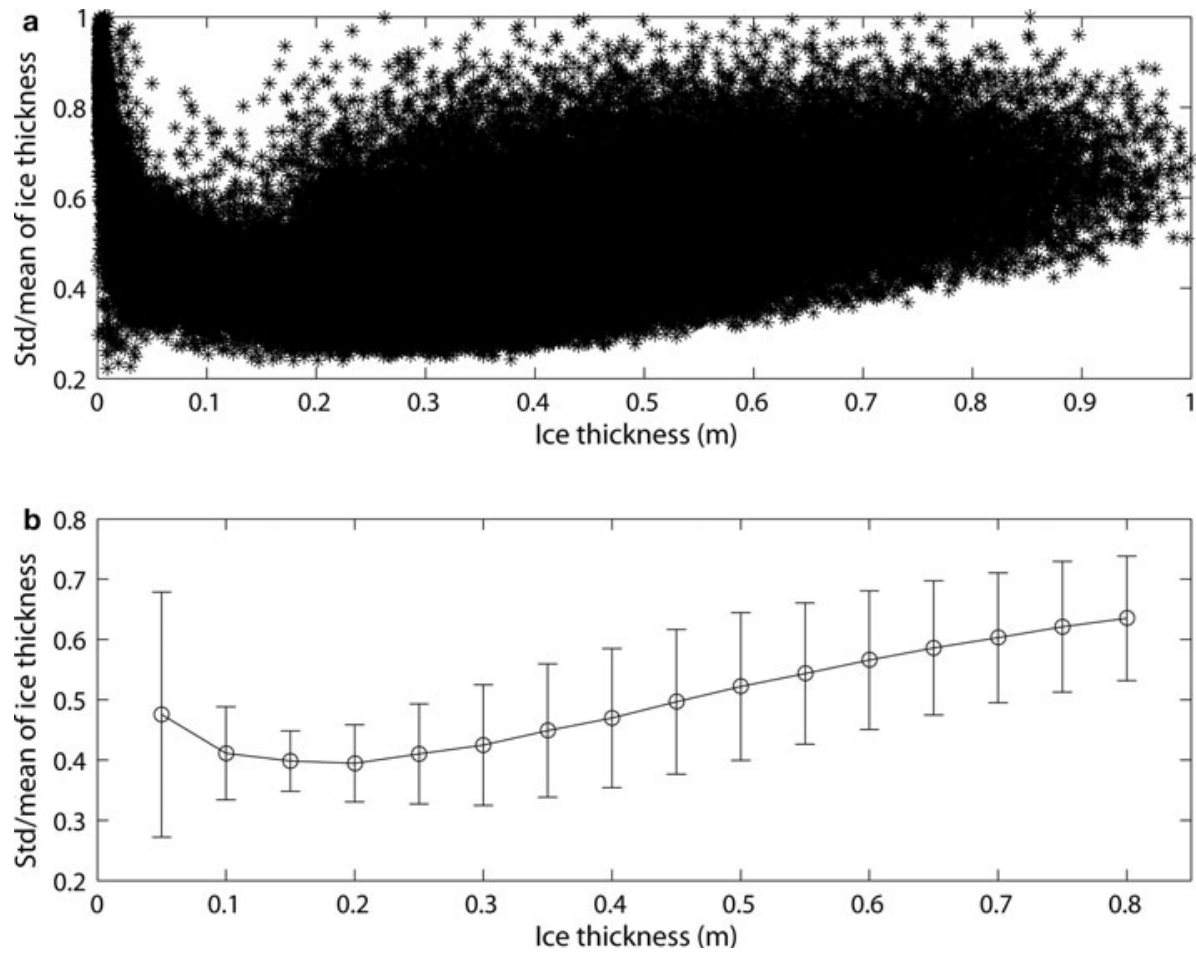

Fig. 4. Uncertainty of the MODIS-based ice thickness estimated with the Monte Carlo method. (a) Mean and std/mean of the sampled thickness values. (b) Average thickness uncertainty as a function of ice thickness and the variation of the uncertainty characterized by std(std/ mean).

Ice thickness uncertainty with the Monte Carlo method Ice thickness uncertainty with the Monte Carlo method is characterized by $\operatorname{std}\left(h_{\mathrm{i}}\right) /$ mean $\left(h_{\mathrm{i}}\right)$, i.e. coefficient of variation (vc), of the sampled $h_{\mathrm{i}}$ values from Eqn (6). The Monte Carlo $h_{\mathrm{i}}$ sampling was conducted only at the HIRLAM gridpoints (20 km spacing), in order to reduce computation burden. $T_{\mathrm{s}}$ is here 3 by 3 pixels average at the gridpoints, to decrease local $T_{\mathrm{s}}$ variation. In total, there were 92123 gridpoint datasets for the $h_{\mathrm{i}}$ sampling. Table 2 shows the estimated, or 'best-guess', standard deviations of the variables needed in the $h_{\mathrm{i}}$ sampling. The chosen std of 0.02 for $b_{1}$ in Eqn (11) represents $40 \%$ vc for $h_{\mathrm{s}}$ when $h_{\mathrm{i}} \leq 20 \mathrm{~cm}$, and $22 \%$ when $h_{\mathrm{i}}>20 \mathrm{~cm}$. For the $T_{\mathrm{a}}, u$ and Rh, stds, instead of RMSEs, from the HIRLAM and weather station data comparison are used because the observed difference distributions are characterized by the mean bias and std. Only correlations between $T_{\mathrm{s}}$ and the HIRLAM $T_{\mathrm{a}}$, $u, \mathrm{Rh}$ and $F_{1}^{\mathrm{dn}}$ are taken into account in the random sampling. These were estimated from the gridpoint data. The correlation is largest, +0.90 , between $T_{\mathrm{a}}$ and $F_{1}^{\mathrm{dn}}$, and second largest, +0.83 , between $T_{\mathrm{s}}$ and $T_{\mathrm{a}}$. For other variable combinations it varied from -0.37 to +0.78 . $T_{\mathrm{s}}$ $T_{\mathrm{a}}, u, \mathrm{Rh}$ and $F_{\mathrm{I}}^{\mathrm{dn}}$ were sampled from a five-dimensional normal distribution. Other variables were also sampled from normal distributions. At each gridpoint, 1000 random $h_{\mathrm{i}}$ values were calculated. Before calculating mean and std for the sampled $h_{\mathrm{i}}$ values, negative un-physical $h_{\mathrm{i}}$ values were rejected, as was the upper $5 \%$ of the positive $h_{\mathrm{i}}$ values. Very large $h_{\mathrm{i}}$ values $\left(h_{i} \gg 1 \mathrm{~m}\right)$ are due to $F_{\mathrm{t}}$ in Eqn (7) having an expected value very close to zero and they would increase $\operatorname{std}\left(h_{\mathrm{i}}\right)$ considerably if not excluded. Next, the $h_{\mathrm{i}}$ values were divided into $5 \mathrm{~cm}$ wide bins, and the mean and std of vc were calculated. The results of the Monte Carlo simulation are shown in Figures 4-6.
The mean vc with all the data is smallest, $39-41 \%$, for the $h_{\mathrm{i}}$ range $10-25 \mathrm{~cm}$ and increases slowly to $64 \%$ when $h_{\mathrm{i}}=80 \mathrm{~cm}$ (Fig. 4). The mean vc is $48 \%$ when $h_{\mathrm{i}}=5 \mathrm{~cm}$ and approaches $100 \%$ when $h_{\mathrm{i}}$ is only $1-2 \mathrm{~cm}$. If the maximum allowable mean vc is set to $50 \%$ then the typical maximum reliable $h_{\mathrm{i}}$ is $\sim 45 \mathrm{~cm}$, and the typical minimum is $4-5 \mathrm{~cm}$. The large vc for very thin ice $\left(h_{\mathrm{i}}<5 \mathrm{~cm}\right)$ does not matter when the $h_{\mathrm{i}}$ charts are used for ship navigation, but can be a drawback when they are used for ocean heat loss calculations.

The large scatter of data points in Figure 4 is partly due to the dependence of the $h_{\mathrm{i}}$ uncertainty on $T_{\mathrm{a}}$ and $u$. Figure 5 shows the mean vc as a function of $T_{\mathrm{a}}$ range. The mean vc clearly decreases with decreasing $T_{\mathrm{a}}$ when $h_{\mathrm{i}}>20 \mathrm{~cm}$. If we again take the vc limit of $50 \%$ for the reliable $h_{\mathrm{i}}$ then the maximum $h_{\mathrm{i}}$ is $60 \mathrm{~cm}$ when $T_{\mathrm{a}}<-30^{\circ} \mathrm{C}$, but it is only $25 \mathrm{~cm}$ when $-20<T_{\mathrm{a}}<-15^{\circ} \mathrm{C}$. For all gridpoint data, the HIRLAM $T_{\mathrm{a}}$ is less than $-20^{\circ} \mathrm{C}$ in $82 \%$ of cases. The mean vc as a function of $u$ range is depicted in Figure 6. The mean vc increases considerably with increasing $u$ when $h_{\mathrm{i}}>10 \mathrm{~cm}$.

Table 2. Standard deviations of the variables used in the Monte Carlo estimation of the MODIS-based ice thickness uncertainty

\begin{tabular}{lclc}
\hline Variable & std & Variable & std \\
\hline$T_{\mathrm{s}}$ & $1.3 \mathrm{~K}$ & $k_{\mathrm{s}}$ & $0.05 \mathrm{~W} \mathrm{~m}^{-1} \mathrm{~K}^{-1}$ \\
$T_{\mathrm{a}}$ & $3.7 \mathrm{~K}$ & $b_{1}$ & 0.02 \\
$u$ & $\begin{array}{c}\text { Function of } u_{1} \\
2.0-5.1 \mathrm{~m} \mathrm{~s}^{-1}\end{array}$ & $S_{\mathrm{i}}$ & $2 \mathrm{ppt}$ \\
$\mathrm{Rh}$ & $12 \%$ & $\varepsilon$ & \\
$F_{\mathrm{l}}^{\mathrm{dn}}$ & $20 \mathrm{~W} \mathrm{~m}^{-2}$ & $C_{\mathrm{s}}, C_{\mathrm{e}}$ & $10 \%$ of expected \\
& & & value
\end{tabular}




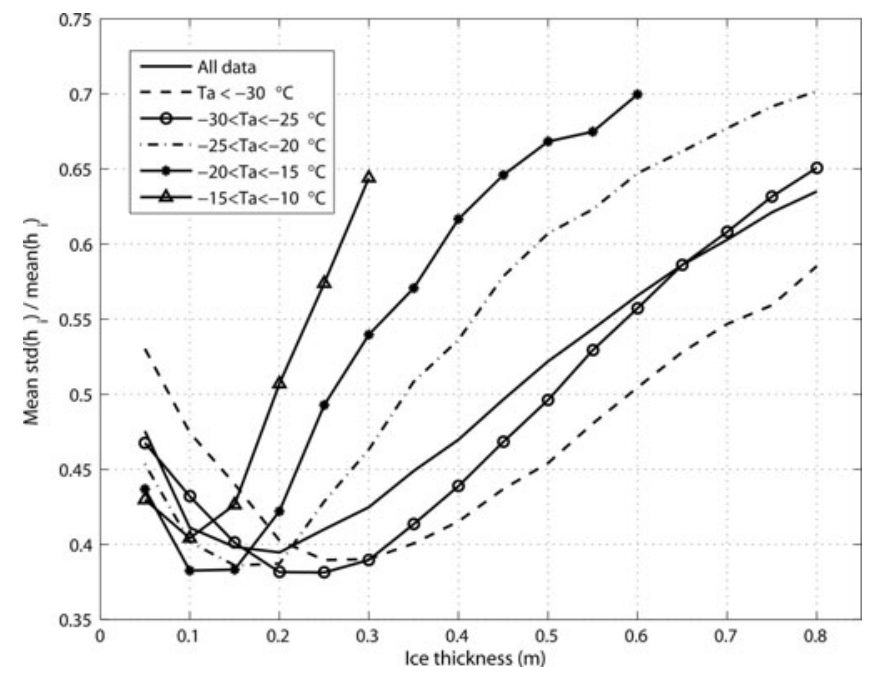

Fig. 5. Average uncertainty of the MODIS-based ice thickness as a function of HIRLAM air temperature range.

With the $50 \% h_{\mathrm{i}}$ uncertainty limit, the maximum $h_{\mathrm{i}}$ is $65 \mathrm{~cm}$ when $u \leq 2 \mathrm{~m} \mathrm{~s}^{-1}$ and only $20 \mathrm{~cm}$ when $7 \leq u \leq 8 \mathrm{~m} \mathrm{~s}^{-1}$. For the gridpoint data, the HIRLAM modal $u$ is $3 \mathrm{~m} \mathrm{~s}^{-1}$ and $83 \%$ of the $u$ values are $<5 \mathrm{~m} \mathrm{~s}^{-1}$. Figures 5 and 6 show that the $h_{\mathrm{i}}$ uncertainty is smallest under very cold calm wind conditions. As the $h_{\mathrm{i}}$ uncertainty depends considerably on $T_{\mathrm{a}}$ and $u$, it is difficult to determine the typical maximum for $h_{\mathrm{i}}$, but under typical weather conditions $\left(T_{\mathrm{a}}<-20^{\circ} \mathrm{C}, u \leq 5 \mathrm{~m} \mathrm{~s}^{-1}\right)$ for the MODIS data the maximum is $\sim 50 \mathrm{~cm}$. The accuracy is best for the $15-30 \mathrm{~cm}$ thickness range, $\sim 38 \%$.

The $h_{\mathrm{i}}$ uncertainty values obtained here are larger than those by Yu and Rothrock (1996). They assessed that the $h_{\mathrm{i}}$ uncertainty increases from $27 \%$ for $20 \mathrm{~cm}$ thick ice to $50 \%$ for $h_{\mathrm{i}}$ around $1 \mathrm{~m}$. However, they estimated much smaller std for $T_{\mathrm{a}}$ and $u$, only $1.6^{\circ} \mathrm{C}$ and $0.7 \mathrm{~m} \mathrm{~s}^{-1}$, respectively. If we decrease std to $1^{\circ} \mathrm{C}$ and $1 \mathrm{~m} \mathrm{~s}^{-1}$ then the $h_{\mathrm{i}}$ uncertainty is $<40 \%$ when $h_{\mathrm{i}}=80 \mathrm{~cm}$, and in the $10-30 \mathrm{~cm}$ range it is only $\sim 22 \%$. When the std of $b_{1}$ is doubled to 0.04 , corresponding to $68 \%$ and $44 \% h_{\mathrm{s}}$ uncertainty when $h_{\mathrm{i}} \leq 20 \mathrm{~cm}$ and $h_{\mathrm{i}}>20 \mathrm{~cm}$, respectively, the $h_{\mathrm{i}}$ uncertainty increases slightly, a $50 \%$ limit being reached when $h_{i}=45 \mathrm{~cm}$. The contribution of different variables to the $h_{\mathrm{i}}$ uncertainty was studied by taking into account std of only one variable at a time in the $h_{\mathrm{i}}$ sampling. The largest $h_{\mathrm{i}}$ uncertainty comes from $T_{\mathrm{a}} . T_{\mathrm{s}}$ and $F_{1}^{\text {dn }}$ have somewhat smaller roughly equal contributions. When $h_{\mathrm{i}}<30 \mathrm{~cm}$ then $u$ also makes a significant contribution to the $h_{\mathrm{i}}$ uncertainty. The $h_{\mathrm{i}}$ uncertainty from snow thickness alone is $\sim 10 \%$. Direct comparison of our results to those of $\mathrm{Yu}$ and Rothrock (1996) and Wang and others (2010) is not possible as they did not use NWP model data in the $h_{\mathrm{i}}$ retrieval, but in their results $F_{\mathrm{l}}^{\mathrm{dn}}$ and $u$ were among the largest error sources.

Comparison of thickness maps from consecutive days The comparison of $h_{\mathrm{i}}$ charts from consecutive days estimates the stability of $h_{\mathrm{i}}$ retrieval when the true $h_{\mathrm{i}}$ change is insignificant, but the forcing data and $T_{\mathrm{s}}$ may undergo large changes in a short period of time. Large $h_{\mathrm{i}}$ differences are mainly due to the cloud-masking errors, HIRLAM data inaccuracies and the frequency and spatial distribution of open leads. Undetected high thin clouds result in a cold bias in $T_{\mathrm{s}}$, making the ice appear thicker than it actually is

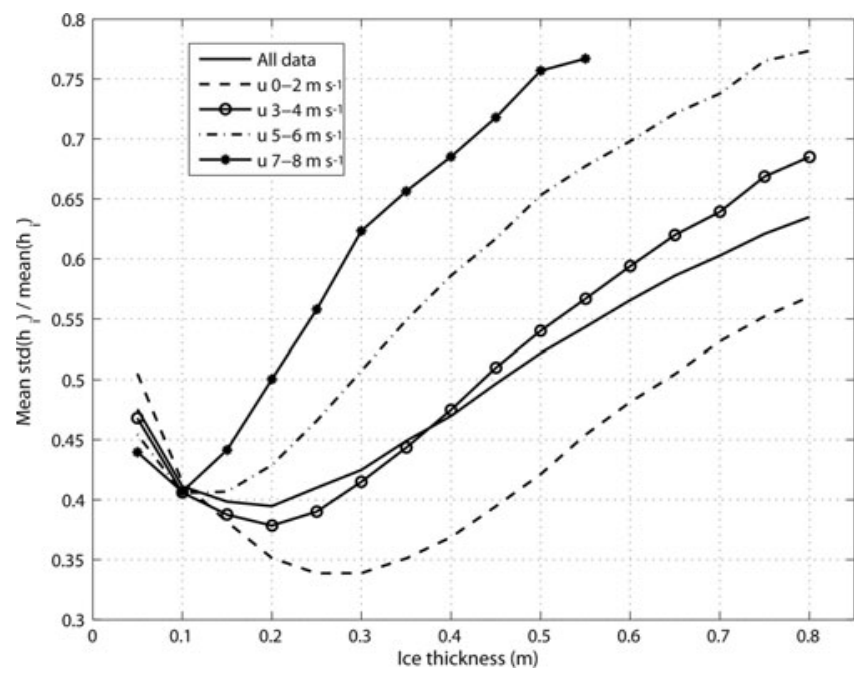

Fig. 6. Average uncertainty of the MODIS-based ice thickness as a function of HIRLAM wind-speed range.

(Martin and others, 2004; Tamura and others, 2006). Ice fog generated by intense vapor flux from leads and polynyas under cold conditions is warmer than surrounding fast- or pack-ice $T_{\mathrm{s}}$ and colder than $T_{\mathrm{s}}$ for thin ice. This leads to $h_{\mathrm{i}}$ underestimation for pack ice and overestimation for thin ice. Hence, the presence of open leads has an unfavorable equalizing effect on the $h_{\mathrm{i}}$ values. The highest lead activity is also usually associated with relatively high wind speeds, which additionally weakens the retrieval accuracy.

For this study, there are $108 h_{\mathrm{i}}$ chart pairs. The time difference between the charts varies from 15 to 33 hours, with an average of 24 hours. During these short time periods the ice growth is typically only a few centimeters (Leppäranta, 1993). $h_{\mathrm{i}}$ differences from the chart pairs were calculated using $10 \times 10 \mathrm{~km}$ block averages in order to diminish the effect of ice movement. For a block with all $h_{\mathrm{i}}$ pixels valid, $\left(0 \leq h_{\mathrm{i}}<1 \mathrm{~m}\right), \operatorname{std}\left(h_{\mathrm{i}}\right) / \operatorname{mean}\left(h_{\mathrm{i}}\right)$ was required to be $<20 \%$ to reject ice areas in the comparison that were too heterogeneous. In total, there were $31560 h_{\mathrm{i}}$ difference values from the chart pairs.

The overall root-mean-square difference (RMS) for the $h_{\mathrm{i}}$ difference data is $8.5 \mathrm{~cm}$, the mean absolute bias is $6.1 \mathrm{~cm}$, and $90 \%$ of the absolute $h_{\mathrm{i}}$ differences are $<14 \mathrm{~cm}$. Within the $h_{\mathrm{i}}$ chart pairs, RMS varies from 2.1 to $19.7 \mathrm{~cm}$ and the average is $8.3 \mathrm{~cm}$. There are no correlations between the $h_{\mathrm{i}}$ and $T_{\mathrm{a}}$ or $u$ differences, but the absolute $T_{\mathrm{a}}$ and $u$ differences are typically small, below $2^{\circ} \mathrm{C}$ and $2 \mathrm{~m} \mathrm{~s}^{-1}$, respectively. This suggests that cloud-masking errors caused the large RMS for some $h_{\mathrm{i}}$ chart pairs. For the $h_{\mathrm{i}}$ intervals $0-10,10-20,20-30$, $30-40,40-50$ and 50-60 cm, RMS is $4.2,4.9,8.4,9.3,11.0$ and $11.7 \mathrm{~cm}$, respectively. RMS is $21-32 \%$ of the $h_{\mathrm{i}}$ bin centre value when the $0-10 \mathrm{~cm}$ bin is excluded. These statistics demonstrate good stability (or repeatability) of the MODIS and HIRLAM data-based $h_{\mathrm{i}}$ charts.

\section{Maximum reliable ice thickness}

Next, typical maximum reliable $h_{\mathrm{i}}$ under different $T_{\mathrm{a}}$ ranges (width $5^{\circ} \mathrm{C}$ ) is studied using empirical mean $T_{\mathrm{a}}-T_{\mathrm{s}}$ vs $h_{\mathrm{i}}$ curves, which show how rapidly $h_{\mathrm{i}}$ changes as a function of a slight change in $T_{\mathrm{s}}$ or $T_{\mathrm{a}}$. These curves were calculated from the $T_{\mathrm{s}}, h_{\mathrm{i}}$ and $T_{\mathrm{a}}$ averages $(3 \times 3$ pixel block) at the HIRLAM gridpoints. As $T_{\mathrm{a}}-T_{\mathrm{s}}$ vs $h_{\mathrm{i}}$ also depends on $u$ it 
was required to be $<5 \mathrm{~m} \mathrm{~s}^{-1}$ to include only the most common wind conditions of the MODIS data. The number of gridpoint datasets was 72955 . Figure 7 shows the mean $T_{\mathrm{a}}-T_{\mathrm{s}}$ vs $h_{\mathrm{i}}$ curves for six different $T_{\mathrm{a}}$ ranges. The mean $h_{\mathrm{i}}$ in the curves was calculated inside $1{ }^{\circ} \mathrm{C}$ wide $T_{\mathrm{a}}-T_{\mathrm{s}}$ bins.

When $T_{\mathrm{a}}-T_{\mathrm{s}}$ approaches $0^{\circ} \mathrm{C}$, the sensitivity of $h_{\mathrm{i}}$ to $T_{\mathrm{a}}-T_{\mathrm{s}}$ increases: a $1{ }^{\circ} \mathrm{C}$ change in $T_{\mathrm{a}}-T_{\mathrm{s}}$ can cause $>10 \mathrm{~cm}$ change in $h_{\mathrm{i}}$. Taking into account the RMSE of $T_{\mathrm{s}}$ and $T_{\mathrm{a}}$ (and other variables in Eqn (6)), this sensitivity is too large for accurate $h_{\mathrm{i}}$ retrieval, whereas when $T_{\mathrm{a}}-T_{\mathrm{s}}=-5^{\circ} \mathrm{C}$, a $1^{\circ} \mathrm{C}$ change leads at maximum to a $4 \mathrm{~cm}$ change in $h_{\mathrm{i}}$. Not only the maximum acceptable $T_{\mathrm{a}}-T_{\mathrm{s}}$ vs $h_{\mathrm{i}}$ sensitivity, but also the $T_{\mathrm{a}}-T_{\mathrm{s}}$ difference itself may be a limiting factor for the maximum reliable $h_{\mathrm{i}}$. When $T_{\mathrm{a}}-T_{\mathrm{s}}>0^{\circ} \mathrm{C}$, then, due to the radiative surface cooling, the snow/ice surface is colder than the air and the simple parameterizations of the turbulent sensible and latent heat fluxes may be liable to large errors, a common problem for the stable boundary layer (Hanna and Yang, 2001; Järvenoja, 2005). We suggest that the maximum allowed $T_{\mathrm{a}}-T_{\mathrm{s}}$ should be $0^{\circ} \mathrm{C}$ or only few degrees higher. Figure 7 shows that at a fixed $T_{\mathrm{a}}-T_{\mathrm{s}}$ value the corresponding mean $h_{\mathrm{i}}$ decreases considerably with increasing $T_{\mathrm{a}}$.

In summary, the maximum reliable $h_{\mathrm{i}}$ depends on (1) maximum acceptable $T_{\mathrm{a}}-T_{\mathrm{s}}$ vs $h_{\mathrm{i}}$ sensitivity, (2) maximum allowed $T_{\mathrm{a}}-T_{\mathrm{s}}$, (3) acceptable $h_{\mathrm{i}}$ uncertainty based on the Monte Carlo simulation, and (4) $T_{\mathrm{a}}$. If we set the maximum $T_{\mathrm{a}}-T_{\mathrm{s}}$ to $0^{\circ} \mathrm{C}$ and the $T_{\mathrm{a}}-T_{\mathrm{s}}$ vs $h_{\mathrm{i}}$ sensitivity to be $<10 \mathrm{~cm}^{\circ} \mathrm{C}^{-1}$, then the maximum $h_{\mathrm{i}}$ varies from $50 \mathrm{~cm}$ when $T_{\mathrm{a}}<-30^{\circ} \mathrm{C}\left(\max T_{\mathrm{s}}-T_{\mathrm{a}}\right.$ now $-2^{\circ} \mathrm{C}$ due to the sensitivity limit) to $35 \mathrm{~cm}$ when $-20 \leq T_{\mathrm{a}}<-15^{\circ} \mathrm{C}$ (max $T_{\mathrm{a}}-T_{\mathrm{s}}=0^{\circ} \mathrm{C}$ ). For the first $T_{\mathrm{a}}$ range, the $h_{\mathrm{i}}$ uncertainty is $<50 \%$, but for the second one the $50 \%$ uncertainty limit decreases the maximum $h_{\mathrm{i}}$ to $25 \mathrm{~cm}$. Combining the results, the typical maximum reliable $h_{\mathrm{i}}$ is $\sim 35-50 \mathrm{~cm}$ under typical weather conditions $\left(T_{\mathrm{a}}<-20^{\circ} \mathrm{C}, u \leq 5 \mathrm{~m} \mathrm{~s}^{-1}\right)$ present in the MODIS data.

\section{CONCLUSIONS}

We have studied ice thickness retrieval in the Kara Sea and eastern part of the Barents Sea using night-time MODIS $T_{\mathrm{s}}$ images and HIRLAM weather forcing data, and conducted detailed accuracy analysis of the retrieved $h_{\mathrm{i}}$ for ice $<1 \mathrm{~m}$ thick. For the cloud masking of the MODIS data we had to use manual methods in order to improve detection of cloudcovered areas, mainly thin clouds and ice fog. These manual methods are not suitable for processing a large number of MODIS images (too time-consuming) or to be included in an operative MODIS $h_{\mathrm{i}}$ chart processing chain.

Our MODIS $h_{\mathrm{i}}$ chart collection of 199 charts spans three winters (November-April) in 2008-11. The temporal coverage of the charts is worst for November and April due to prevailing cloud cover, and best for February and March. Over the northwestern (Barents Sea) and southwestern (Pechora Sea) parts of our study area (Fig. 1) the temporal and spatial $h_{\mathrm{i}}$ chart coverage is typically too small to follow development of thin-ice areas (leads, polynyas).

We conducted detailed accuracy analysis of the retrieved $h_{\mathrm{i}}$ using three different methods, taking into account the inaccuracy of the HIRLAM weather forcing data, and determined maximum reliable $h_{\mathrm{i}}$ values under different $T_{\mathrm{a}}$ and $u$ ranges. The typical maximum reliable $h_{\mathrm{i}}$ is $35-50 \mathrm{~cm}$ under typical weather conditions $\left(T_{\mathrm{a}}<-20^{\circ} \mathrm{C}, u \leq 5 \mathrm{~m} \mathrm{~s}^{-1}\right)$ present in the MODIS data. The accuracy is best for the

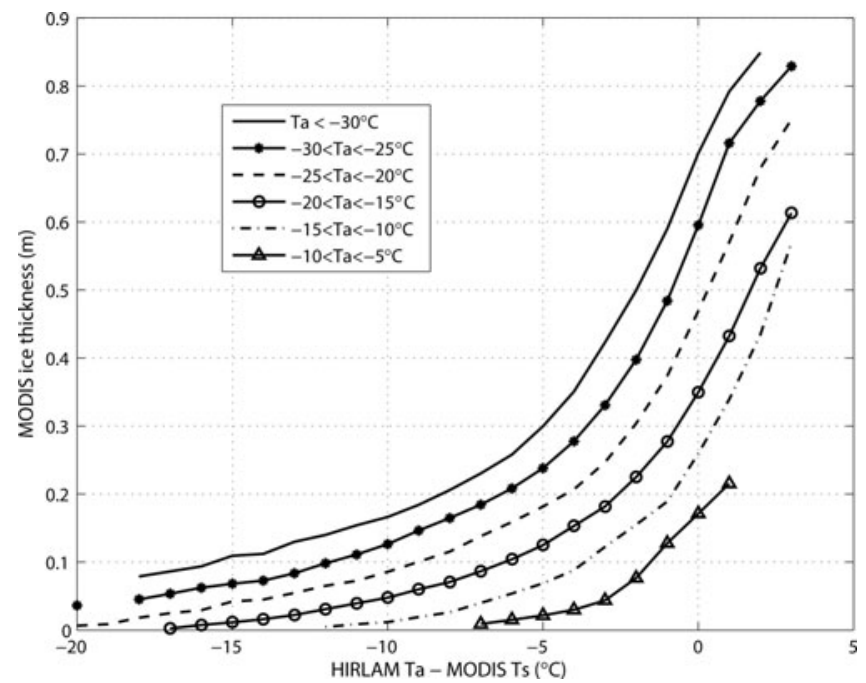

Fig. 7. Empirical average relationship between the HIRLAM air temperature and MODIS ice surface temperature difference and the retrieved ice thickness for different air temperature ranges.

$15-30 \mathrm{~cm}$ thickness range, $\sim 38 \%$. Our $h_{\mathrm{i}}$ limits are more conservative than those in previous studies ( $\mathrm{Yu}$ and Rothrock, 1996; Wang and others, 2010) where NWP model data were not used in the $h_{\mathrm{i}}$ retrieval. The large difference from the maximum $h_{\mathrm{i}}$ of $2.8 \mathrm{~m}$ estimated by Wang and others (2010) is likely also due to the APP-x dataset (25 km pixel size, $T_{\mathrm{s}}$ corrected with ice concentration data) used in that study. A straightforward way of increasing the accuracy of our MODIS-based $h_{\mathrm{i}}$ is to increase the accuracy of the NWP forcing data, if possible. Further studies include $h_{\mathrm{i}}$ retrieval using snow thickness information from microwave radiometer data or from a sea-ice thermodynamic model, and the effect of the ice deformation derived from SAR data on the $h_{\mathrm{i}}$ accuracy.

Our results give new detailed insight into the capability of $T_{\mathrm{s}}$-based $h_{\mathrm{i}}$ retrieval in the Arctic marginal seas during freeze-up and wintertime, and should also benefit work on microwave-radiometer-based $h_{\mathrm{i}}$ retrieval where $T_{\mathrm{s}}$-based $h_{\mathrm{i}}$ charts are used for algorithm development and validation.

\section{REFERENCES}

Doronin YuP (1971) Thermal interaction of the atmosphere and the hydrosphere in the Arctic. Israel Program for Scientific Translations, Jerusalem

Frey RA and 6 others (2008) Cloud detection with MODIS. Part I: Improvements in the MODIS cloud mask for Collection 5. J. Atmos. Oceanic Technol., 25(7), 1057-1072 (doi: 10.1175/ 2008JTECHA1052.1)

Hall DK, Key J, Casey KA, Riggs GA and Cavalieri DJ (2004) Sea ice surface temperature product from MODIS. IEEE Trans. Geosci. Remote Sens., 42(5), 1076-1087 (doi: 10.1109/ TGRS.2004.825587)

Hall DK, Riggs GA and Salomonson VV (2007) (updated daily) MODIS/Terra Sea Ice Extent 5-Min L2 Swath $1 \mathrm{~km}$, Version 5. National Snow and Ice Data Center, Boulder, CO. Digital media: http://nsidc.org/data/mod29v5.html [Nov-Apr, 2008-2011]

Hanna SR and Yang R (2001) Evaluations of mesoscale models' simulations of near-surface winds, temperature gradients, and mixing depths. J. Appl. Meteorol., 40(6), 1095-1104 (doi: 10.1175/1520-0450(2001)040<1095:EOMMSO > 2.0.CO;2)

Järvenoja S (2005) Problems in predicted HIRLAM T2m in winter, spring and summer. In Proceedings of 4th SRNWP/HIRLAM 
Workshop on Surface Processes, Surface Assimilation and Turbulence, 15-17 September 2004. Norrköping, Sweden. Swedish Meteorological and Hydrological Institute, Norrköking, 14-26 http://srnwp.met.hu/workshops/Norrkoping_2004/index.htm

Kaleschke L, Tian-Kunze X, Maaß N, Mäkynen M and Drusch M (2012) Sea ice thickness retrieval from SMOS brightness temperatures during the Arctic freeze-up period. Geophys. Res. Lett., 39(5), L05501 (doi: 10.1029/2012GL050916)

Källén E ed (1996) HIRLAM documentation manual, system 2.5. Swedish Meteorological and Hydrological Institute, Norrköping

Kovacs A (1996) Sea ice. Part 1. Bulk salinity versus ice floe thickness. CRREL Rep. 96-7.

Kwok R and Rothrock DA (2009) Decline in Arctic sea ice thickness from submarine and ICESat records: 1958-2008. Geophys. Res. Lett., 36(15), L15501 (doi: 10.1029/2009GL039035)

Kwok R, Nghiem SV, Yueh SH and Huynh DD (1995) Retrieval of thin ice thickness from multifrequency polarimetric SAR data. Remote Sens. Environ., 51(3), 361-374 (doi: 10.1016/00344257(94)00017-H)

Laxon S, Peacock N and Smith D (2003) High interannual variability in sea ice thickness in the Arctic region. Nature, 425(6961), 947-950 (doi: 10.1038/nature02050)

Leppäranta M (1993) A review of analytical models sea-ice growth. Atmos.-Ocean, 31(1), 123-138 (doi: 10.1080/07055900.1993. 9649465)

Lüpkes C, Vihma T, Birnbaum G and Wacker U (2008) Influence of leads in sea ice on the temperature of the atmospheric boundary layer during polar night. Geophys. Res. Lett., 35(3), L03805 (doi: 10.1029/2007GL032461)

Martin S, Drucker R, Kwok R and Holt B (2004) Estimation of the thin ice thickness and heat flux for the Chukchi Sea Alaskan coast polynya from Special Sensor Microwave/Imager data, 1990-2001. J. Geophys. Res., 109(C10), C10012 (doi: 10.1029/ 2004JC002428)

Nakamura K, Wakabayashi H, Uto S, Naoki K, Nishio F and Uratsuka S (2006) Sea-ice thickness retrieval in the Sea of Okhotsk using dual-polarization SAR data. Ann. Glaciol., 44, 261-268 (doi: 10.3189/172756406781811420)

Nakamura K, Wakabayashi H, Uto S, Ushio S and Nishio F (2009) Observation of sea-ice thickness using ENVISAT data from Lützow-Holm Bay, East Antarctica. IEEE Trans. Geosci. Remote Sens., 6(2), 277-281 (doi: 10.1109/LGRS.2008.2011061)

National Snow and Ice Data Center (NSIDC) (2004) Morphometric characteristics of ice and snow in the Arctic Basin: aircraft landing observations from the former Soviet Union, 1928-1989. Compiled by I.P. Romanov. National Snow and Ice Data Center,
Boulder, CO. Digital media: http://nsidc.org/data/docs/noaa/ g02140_romanov_arctic_seaice/index.html

Nihashi S, Ohshima KI, Tamura T, Fukamachi Y and Saitoh S (2009) Thickness and production of sea ice in the Okhotsk Sea coastal polynyas from AMSR-E. J. Geophys. Res., 114(C10), C10025 (doi: 10.1029/2008JC005222)

Similä M, Mäkynen M and Heiler I (2010) Comparison between C band synthetic aperture radar and 3-D laser scanner statistics for the Baltic Sea ice. J. Geophys. Res., 115(C10), C10056 (doi: 10.1029/2009JC005970)

Singh RK, Oza SR, Vyas NK and Sarkar A (2011) Estimation of thin ice thickness from the advanced microwave scanning radiometer-EOS for coastal polynyas in the Chukchi and Beaufort seas. IEEE Trans. Geosci. Remote Sens., 49(8), 2993-2998 (doi: 10.1109/TGRS.2011.2123101)

Sturm M, Holmgren J, König M and Morris K (1997) The thermal conductivity of seasonal snow. J. Glaciol., 43(143), 26-41

Tamura T and Ohshima KI (2011) Mapping of sea ice production in the Arctic coastal polynyas. J. Geophys. Res., 116(C7), C07030 (doi: 10.1029/2010JC006586)

Tamura T and 6 others (2006) Estimation of thin sea-ice thickness from NOAA AVHRR data in a polynya off the Wilkes Land coast, East Antarctica. Ann. Glaciol., 44, 269-274 (doi: 10.3189/ 172756406781811745)

Undén P and 26 others. (2002) The high resolution limited area model. HIRLAM-5 scientific documentation. Swedish Meteorological and Hydrological Institute, Norrköping (Technical Report)

Untersteiner N (1964) Calculations of temperature regime and heat budget of sea ice in the central Arctic. J. Geophys. Res., 69(22), 4755-4766 (doi: 10.1029/JZ069i022p04755)

Wakabayashi H, Matsuoka T, Nakamura K and Nishio F (2004) Polarimetric characteristics of sea ice in the Sea of Okhotsk observed by airborne L-band SAR. IEEE Trans. Geosci. Remote Sens., 42(11), 2412-2425 (doi: 10.1029/JZ069i022p04755)

Wang X, Key JR and Liu Y (2010) A thermodynamic model for estimating sea and lake ice thickness with optical satellite data. J. Geophys. Res., 115(C12), C12035 (doi: 10.1029/ 2009JC005857)

Yu Y and Rothrock DA (1996) Thin ice thickness from satellite thermal imagery. J. Geophys. Res., 101(C11), 25 753-25766 (doi: 10.1029/96JC02242)

Zhang Z, Cheng B, Launiainen J, Wu H and Liu Y (2006) Intercomparisons of thermodynamic sea-ice modeling results using various parameterizations of radiative flux. Acta Oceanol. Sin., 25(1), 21-31 